\title{
HIJAS DE ILÉ: O EL FECHIZO MÁS GRANDE, CONVERTIR NIÑAS EN MUJERES
}

\author{
Mae pequeña Skuld Wollo - Maria Azul di Baja ${ }^{1}$ \\ Yabba Skadi Wollo ${ }^{2}$ \\ Kaira Wollo ${ }^{3}$
}

DOI 10.26512/revistacalundu.v4i1.32238

Somos un grupo de mujeres criadas entre los años '80 y los '90 en una Argentina apenas salida de la dictadura. Mae Pequeña Skuld Wollo, académicamente reconocida como María Azul Di Baja, profesora de Expresión Corporal egresada de la Universidad Nacional de las Artes, con tesis en proceso de la carrera del posgrado de "Pedagogías para la Igualdad en Contextos Socioeducativos Diversos, especialización en géneros y sexualidades" de la Universidad de Buenos Aires, feminista activista y trabajadora en el campo de la niñez y la adolescencia en espacio socioeducativo con personas en situación de vulnerabilidad social. Yaba Skady Wollo cosmetóloga, peluquera, bartender y gestión de bares y barras, estudiante de astrología. Hija de fe Kaira Wollo, matriculada en despacho de aeronaves y tripulante de cabina de pasajeros, actualmente líder de equipo de soporte en empresa de sistemas ERP y HIS. Las tres, miembros del Ilé Nueva Conciencia.

Desde niñas, la televisión nos mostraba mujeres peleando contra mujeres por hombres, a nuestro presidente ostentando lujos y excesos en público; todavía existía la carátula "Crímenes pasionales" justificando y romantizando la violencia de género; dónde el aborto, la Educación Sexual y las pastillas anticonceptivas eran para putas; y a la homosexualidad la aceptábamos, pero no la entendíamos.

Si bien teníamos figuras emblemáticas en la historia inmediatamente anterior a nuestro nacimiento, el poder era de y para los hombres.

En ese momento social, solo había un puñado de maes de santo reconocidas intelectual y espiritualmente, ya que a las mujeres se les exigía tener estudios, capital y/o prestigio.

\footnotetext{
${ }^{1}$ Ilé Nueva Conciéncia. E-mail: azuldibaja@hotmail.com

${ }^{2}$ Ilé Nueva Conciéncia. E-mail: Julianarizzo60@ gmail.com

${ }^{3}$ Ilé Nueva Conciéncia. E-mail: barbararizzo@ @otmail.com.ar
} 
En este contexto, recién iniciada, la Mae Patricia comienza a recibir entidades femeninas en terreiros con estructuras patriarcales, dónde por elección personal iba casi disfrazada, ocultando su cuerpo para evitar el acoso, el enfrentamiento con otras mujeres y la cosificación de su persona.

\section{La resistencia}

Vovó Luiza, nuestra Preta Velha, en épocas de esclavitud era ama de crianza de los hijos de blancos, con el paso del tiempo estos niños crecieron y ella envejeció. Si bien no le dieron su libertad, le permitieron permanecer en su casita dentro de la Fazenda, un lugar apartado e improductivo. Allí, mientras aún cocinaba para la casa grande, hizo provecho de sus beneficios, en tanto que le servía para postergar el comienzo de las tareas de los niños, todos los que ella pudiera esconder. Allí recibió también a otros Pretos Velhos que habían sido librados a su suerte una vez cumplidos 60 años, cuando ya no eran necesarios para sus amos.

Juntos armaban la logística de la fuga de los pocos jóvenes que se animaban a escapar, haciéndose cargo también de los niños que quedaban huérfanos.

Una relación similar entabló con los Caboclos con quienes intercambiaba conocimientos y a cuyos hijos también cuidaba y alimentaba.

Nuestra Preta Velha, utilizó su astucia y operó como agente de resistencia y libertad.

A pesar de todo lo vivido y sufrido, no guardó rencor hacia los blancos, enseñándonos que no hay diferencia entre razas, sexo o creencias religiosas. El bien se derrama por igual sobre todos.

\section{La Resiliencia}

Nema, nuestra joven Bahiana, nació mestiza debido a la violación sistematizada por parte del blanco como práctica aceptaba socialmente. Por esta misma práctica, ella tuvo un hijo inapropiadamente blanco, que era tan parecido al capataz que decidieron sacarlo de la Fazenda.

Nema enloqueció de dolor, y si bien esto no fue motivo para liberarla, la dejaron vagar fuera de la propiedad a su suerte.

En su mente fuera de si, el único pensamiento que cabía era llegar al puerto antes que zarpara el barco con su hijo y el resto de la mercancía. En el camino se encontró con 
los caboclos, ellos la acogieron en su comunidad y la envolvieron en una espiritualidad concordante con la de sus raíces. La guiaron hacia su destino, pero luego ella quedaría allí, en el puerto, varada ejerciendo la prostitución y falleciendo finalmente de tuberculosis, sin encontrar a su hijo.

Acogida por las grandes mujeres de astral, ganó la posibilidad de ser guía espiritual.

Nema vivió en la marginalidad y murió como la más pobre entre los pobres, pero nunca perdió su luz y con ella alumbra la oscuridad de cada una de las personas que se paran frente a ella y su profunda compresión, aconsejando, por ejemplo, sobre adicciones, un tema de alto resentimiento social que nos vuelve a sumergir en la marginalidad.

\section{La libertad ejercida con desparpajo}

¿Qué decir de la famosa María Padilha? Mujer atrevida y rebelde que desafió al status quo y las instituciones en cada una de sus encarnaciones, manteniendo este mismo carácter como guía espiritual y enseñando que la mujer lejos de ser un ser débil y dependiente, puede aspirar a una vida acorde con sus deseos, igualando éticamente estos a la necesidad.

Si tomamos solo un par de ejemplos, esto queda claro.

Cómo cuando se escapaba por las noches del palacio dónde era cortesana, poniendo en riesgo su status y comodidad para ir practicar y aprender lo que era su pasión, la magia, exponiéndose a ser atrapada y quemada viva. O como cuando libró un movimiento de resistencia en el cabaret donde ella tenía el rol de madama, enfrentándose con los soldados armados que habían enviado por ellas. Los tomaron por sorpresa, ellos esperaban encontrar mujeres sumisas ante el peligro, pero se encontraron con mujeres listas para la batalla. Ellas lucharon y huyeron, los soldados las persiguieron y cazaron. Algunas de ellas sobrevivieron más tiempo y otras menos, pero vivieron como ellas lo decidieron.

A lo largo de los años hemos conocido otras Pombagiras que reconocieron a nuestra señora y todas han compartido esta historia con orgullo y agradecimiento, alegando que la forma en la que murieron no tiene relevancia, sino que lo hicieron siendo mujeres libres. 
Así es como nos han empapado de consejos desde sus distintas experiencias de vida y nos han inspirado a través del trabajo en el plano astral y terrenal que han realizado y hemos presenciado, cambiaron vidas.

Mujeres adictas, enfermas, locas, al borde del suicidio, avergonzadas por su sexualidad y su género, madres solteras abandonadas y golpeadas, adolescentes a la deriva, todas ellas pasaron por la casa.

Dignificadas, aprendiendo a utilizar nuestras debilidades, no como excusa o justificación, sino como el piso para trascender cualquiera de las situaciones que se presenten, respetando y nutriendo nuestras cualidades individuales; impulsando nuestros talentos y pasiones; apelando al estudio y la formación como un gran elemento emancipador y como responsabilidad espiritual; a hacernos de las herramientas para no permitir que nadie nos oprima o nos obligue a hacer aquello que no deseamos.

Ellas nos incitan e incluso nos desafían cuando el momento lo requiere, a ganarnos nuestro reconocimiento público a puro mérito y esfuerzo (nunca de prestado, nunca por lo externo, NUNCA pisoteando a otros); debemos tener noción de qué, cómo y por qué accionamos de tal o cual forma y de ninguna manera podemos sentirnos con el derecho de ejercer poder por sobre la voluntad de los demás. Sino más bien tener el coraje para defender la nuestra

Nos recuerdan cada vez que lo necesitamos que nuestro valor no depende de nadie más que de nosotras y que cuando no lo encontramos, están ellas para volvernos a aconsejar con paciencia y amor infinito; y cuando aun así no vemos con claridad, nos sostienen hasta que todo pase. Ellas siempre pudieron, siempre siguieron y nosotras somos sus más orgullosas, devotas y leales discípulas, también podemos. Ellas nos guían.

"El Viejo" es nuestro jefe ancestral, él ocupa un lugar paternal para nosotras. Sus encarnaciones se remontan a miles de años, razón por la cual trae consigo un concepto de la mujer anterior al impuesto por el dogma occidental propio de la iglesia católica apostólica romana: una mujer salvaje, sin miedo.

Nos enseñó que la igualdad y la equidad son la manera correcta y postuló estos valores en el plano astral a través de sus propias acciones como en aquella primera ofrenda que realizamos, dónde él, desde su lugar de jefe, le promete a María Padilha que siempre 
que el recibiera, ella recibiría lo mismo. La unión hace la fuerza y ellos dos, la predican y demuestran.

A lo largo de estos treinta años hemos podido asistir a las entidades trabajando en casos de violencia de género ejercida de múltiples formas, y es así como en nuestro recorrido hemos podido aprender diversas estrategias para asistir a otras mujeres y también repensarnos a nosotras mismas en nuestra vida cotidiana frente a las lógicas patriarcales que a veces, sin quererlo, nosotras mismas reproducimos.

En esta fórmula de contención no podemos dejar de mencionar a nuestra Mae Patricia quien es la encargada de mantener y perpetuar el mensaje de sus ancestros día a día y a quien nosotras recurrimos cada vez que sentimos que las situaciones nos superan.

Nuestra Mae, como antes relatamos, en un comienzo era una mujer que debido a su llamativa belleza recibía la atención equivocada de los Pais y hermanos. Sentía inseguridad y miedo a que por las propuestas que éstos le hacían, nunca pudiera ser tomada seriamente y decepcionar a sus guías. Muchos fueron los lugares donde se repitió este patrón. Siempre a tiempo y bien guiada por sus entidades, supo irse de estos espacios y permanecer en aquellos donde pudiese nutrirse de una carrera espiritual, profundizando en sus intereses intelectuales y respetando su propia esencia, para luego convertirse en la cabeza de la casa y sacerdotisa a la que le consultarían posteriormente todos esos Pais que intentaron limitar su valor.

Nuestra educación como hijas de fe nos impulsó a romper con los estereotipos y expectativas que la sociedad tenía de nosotras. Si bien muchas veces se nos tildó de ser mujeres excesivas, excesivamente fuertes, provocativas, reaccionarias y soberbias, hoy nosotras no tenemos preocupación alguna por ser rotuladas de esa forma, ya que, si la sociedad nos quiere devotas y sumisas, no hay halago mejor que aquel que nos reconoce distantes de esa idea, celebrando así cada día nuestra esencia particular de ser mujeres conectadas con nuestro lado más salvaje, mujeres fuertes y libres.

Para culminar este texto queremos incluir una reflexión que nuestra Mae Patricia una vez supo transmitirnos y que consideramos importante compartir con quienes lean este artículo ya que define el posicionamiento feminista que tiene la casa. 
Yo no creo que haya superioridad entre hombres y mujeres, el desequilibrio de fuerzas es lo que nos ha llevado a este momento en que pareciera que el espíritu de la humanidad ha dejado de evolucionar. Así como la mitología nos remite a un matriarcado anterior en donde la mujer proponía la fertilidad y prosperidad, la promesa de vida para todo ser quedo truncada con la aparición de los grandes héroes conquistadores que derramando sangre fundaron imperios sobre los que basaron su fama y fortuna. Deberá volver una época en que el ser humano, cansado de matar y morir decida unar fuerzas, y el género sea lo menos importante, sino la reconstrucción de un mundo para todos.

Recebido em: 13/04/2020

Aceito em: 14/05/2020 